\title{
In vitro quantitative analysis of Salmonella typhimurium preference for amino acids secreted by human breast tumor
}

\author{
Eunpyo Choi, Bohee Maeng, Jae-hun Lee, Hyung-kwan Chang and Jungyul Park* (D)
}

\begin{abstract}
Bacterial therapies have been paid significant attentions by their ability to penetrate deep into the solid tumor tissue and its propensity to naturally accumulate in tumors of living animals. Understanding the actual mechanism for bacteria to target the tumor is therapeutically crucial but is poorly understood. We hypothesized that amino acids released from the specific tumors induced bacteria to those tumors and the experiments for chemotactic response of bacteria toward the cancer secreting amino acids was then performed by using the diffusion based multiple chemical gradient generator constructed by in situ self-assembly of microspheres. The quantitative analysis was carried out by comparison of intensity using green fluorescent protein (GFP) tagged Salmonella typhimurium (S. typhimurium) in the gradient generator, which showed the clear preference to the released amino acids, especially from breast cancer patients. The understanding chemotaxis toward the cancer secreting amino acids is essential for controlling S. typhimurium targeting in tumors and will allow for the development of bacterial therapies.
\end{abstract}

\section{Background}

Bacteria have been considered as an alternative theranostic activities to overcome the chemotherapeutics barrier [1-4]. The conventional therapy using anticancer drugs, which are capable of diffusing passively, are limited by their inability to penetrate into the tumor tissue and have poor cell susceptibility $[1,5,6]$. Moreover, the chemotherapy can be harmful to other types of normal cells in the process of treating cancer cell with side effects [4]. To date, the bacteria, which have the motile and easy genetic manipulation capability, could overcome the limitations by their ability to penetrate deep into the solid tumor tissue and its propensity to naturally accumulate in tumors of living animals $[1,4]$. Especially, Salmonella typhimurium (S. typhimurium) has been drawn significant attentions for the cancer therapies because several bacteria strains, such as Escherichia coli, Serratia marcescens, and Magnetotactic bacteria strains (Magnetospirillum

\footnotetext{
*Correspondence: sortpark@sogang.ac.kr

Department of Mechanical Engineering, Sogang University, 35 Baekbeom-ro, Mapo-gu, Seoul 121-742, South Korea
}

gryphiswaldense strain MSR-1, Magnetospirillum magnetotacticum strain MS-1, Magnetospirillum magneticum strain AMB-1, and Magnetococcus strain MC-1) have complex incubation procedure and drug resistance against antibiotics and pathogenicity in living animals $[4,7]$. Recently, a number of researches have shown that the S. typhimurium preferentially accumulate 2000 -fold more in tumors than in liver, spleen, lung, heart, and skin $[1,8,9]$. Moreover, because of propensity of S. typhimurium to naturally accumulate in tumors of small living animals, particularly hypoxic tumors, the S. typhimurium for treatment and diagnosis of colorectal and breast cancers has been extensively studied $[4,8,10-12]$.

Although the understanding an actual mechanism for bacteria to target the tumor is therapeutically crucial, the mechanisms of the bacterial motility toward tumors are unclear. Therefore, for further clinical applications, i.e., for effective bacterial therapies, it is important to investigate and clarify the actual mechanism by which bacteria target cancer. One of the possible mechanisms is the positive chemotaxis toward amino acids released from tumors. Tumors are known to possess and release the high concentration of amino acids, such as aspartate, 
serine, alanine, glutamine, glutamate, and etc., compared with the surrounding normal tissues [13].

In this paper, we used the diffusion based multiple chemical gradient generations using in situ self-assembly of microspheres in microchannels [14] (see Fig. 1), to verify the chemotactic preference of $S$. typhimurium for the tumor secreting amino acids, especially for the breast cancer. Recently, many in vitro studies have shown the diffusion-based microfluidic devices for the chemical gradient generation. Specifically, the hydrogel membrane based microfluidic devices have been developed because hydrogels allow similar diffusion conditions to the water [14-17]. The most critical drawback of hydrogel member based system, however, is that the hydrogels are not robust without an aqueous environment and the volume of the hydrogels can be changed significantly depending on the amount of the water absorption [14]. Moreover, the diffusion-based microfluidic devices which can generate the multiple chemical gradients have been developed [18-21]. Nevertheless, these devices have some drawbacks as comparing with the proposed device. In some cases, the devices were constructed with complex multilayered microfluidic parts so that it is complicated to fabricate the devices [18-20]. In other case, it is not easy to realize the spatio-temporal control of the chemical gradient direction [21].

In order to assess the chemotactic preference of $S$. typhimurium for the breast cancer, the reference values of amino acid concentration in serum from breast cancer patients and healthy donors were sought firstly and among these amino acids, the lowest values of the threshold concentration (concentration of attractant that induces an accumulation of bacteria in the capillary significantly greater than that obtained absence of attractant) were then chosen. Next, the amino acids were introduced simultaneously into the gradient generation device to mimic the surround environment of the tumor. Lastly, the quantitative analysis of $S$. typhimurium preference for human breast tumor secreting amino acids was performed. We believe that this understanding chemotaxis toward the cancer secreting amino acids is essential for controlling S. typhimurium targeting in tumors and will allow for the development of bacterial therapies.

\section{Methods}

\section{Fabrication process of PDMS microfluidic channel}

Figure 2a shows schematic diagrams that describe the procedures for fabricating microfluidic devices with multilayered design as we previously reported [14]: The negative photoresist (SU-8 2025, Microchem Corp.) was pipetted on top of the 4-inch silicon wafer and was then spin-coated to form the first layer, i.e. the shallow channel. The spin coated silicon wafer was then soft-baked for several minutes. Subsequently, the wafer was exposed under a mask using an MA-6 aligner (Karl-suss, Germany) and was then placed on a hot-plate for several minutes of post-exposure baking, followed by a short relaxation time. Then the pattern was developed in SU-8 developer. SU-8 2050 was then patterned onto the first SU-8 layer for the second layer, i.e., deep channel, as the same process as above. Next, the $\mathrm{SU}-8$ patterned silicon master was silanized with (tridecafluoro-1,1,2,2,-tetrahydrooctyl)1-trichlorosilane (Sigma Chemical Co., St. Louis, MO, USA) to reduce adhesion between the master and the newly fabricated polydimethylsiloxane (PDMS) based microfluidic devices. A 10:1 PDMS base to curing agent (Sylgard 184, Dow Corning) mixture was then poured to cover the SU-8 patterned silicon master and the PDMS was cured at $95{ }^{\circ} \mathrm{C}$ for $1 \mathrm{~h}$. After the cured PDMS channel was peeled off from the master, cutting into the each

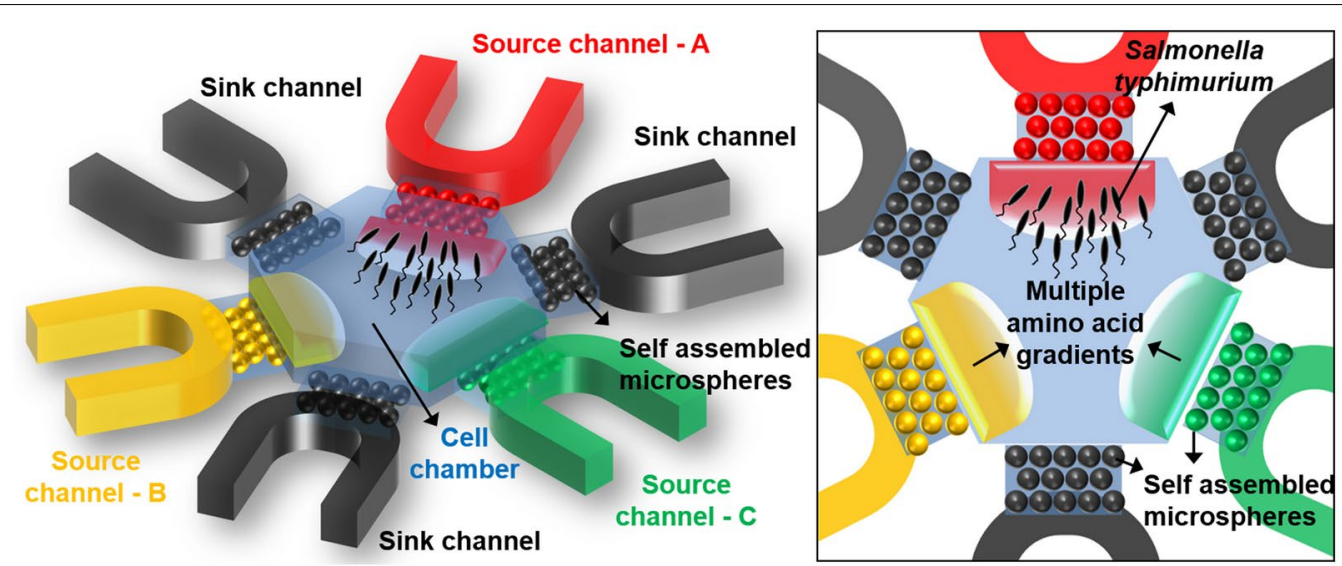

Fig. 1 Schematic representation of the multiple chemical gradients generator for in vitro assay for bacterial preference toward cancer secreting amino acids. 3D view (a) and top view (b) of the device 


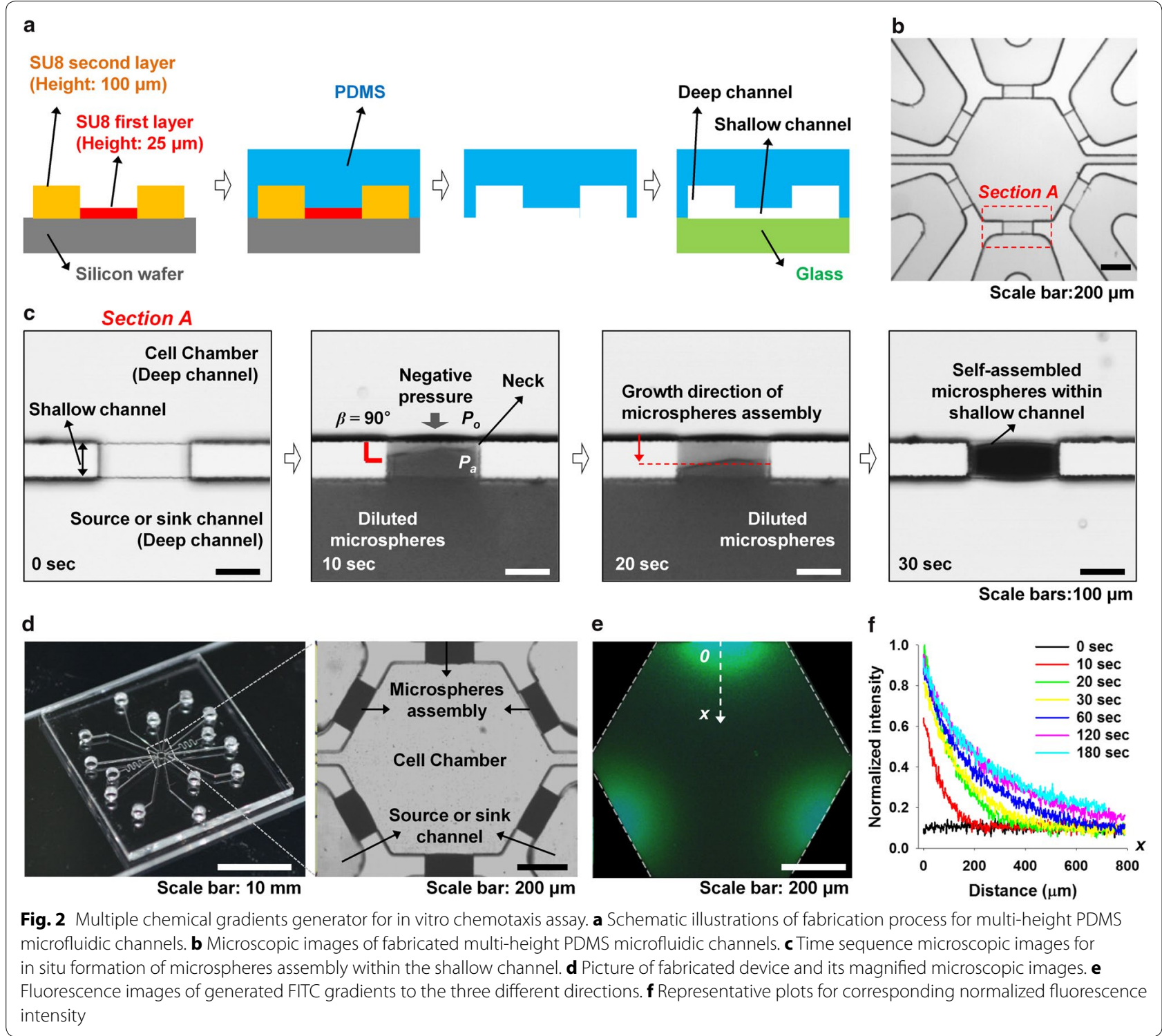

device and punching the inlet and outlet was followed. Finally, the PDMS devices and a slide glass were plasma treated $\left(50 \mathrm{sccm}\right.$ of $\mathrm{O}_{2}$ and $\left.70 \mathrm{~W}\right)$ for $40 \mathrm{~s}$ in an $\mathrm{O}_{2}$ plasma machine (Cute-MP, Femto Science, Korea) and were then bonded each other to form the microfluidic channels.

\section{In situ formation of microchannel networks using microparticles}

Figure 2c shows the time sequence microscopic images for a formation of the microchannel networks using microspheres within the shallow channel, as reported previously [14, 22-25]. The PDMS device with shallow channel and deep channels (source/sink channel and center chamber) were fabricated as shown in Fig. 2b. The diluted silica microspheres with diameter of $1 \mu \mathrm{m}$ (Polyscience Inc.,
Warrington, USA) in $70 \%$ ethanol $(\mathrm{v} / \mathrm{v})$ were then introduced into the source channel (deep channel) by capillary pressure. The diluted microspheres at the interface between shallow and deep channel experience a sudden pressure drop, which tries to drag the solution in the deep channel into the shallow channel [26]. The diluted microspheres at the intersection between shallow and source channel (deep channel) experience a sudden pressure drop $\left(\Delta P_{12}\right)$, which tries to drag the solution in the deep channel into the shallow channel $\left(F_{\text {shallow }}\right)$ [26]. When this flow of solution in shallow channel is located at the neck (interface between the shallow channel and the cell chamber i.e., deep channel), the pressure difference $\left(\Delta P_{n}\right)$ between inside $\left(P_{a}\right)$ and outside $\left(P_{0}\right)$ the solution is induced and it can be expressed as below [27]: 


$$
\begin{aligned}
\Delta P_{n} & =P_{a}-P_{0} \\
& =-\sigma\left(\frac{\cos \theta_{T}+\cos \theta_{B}}{h_{s}}+\frac{\cos \left(\theta_{L}+\beta\right)+\cos \left(\theta_{R}+\beta\right)}{w_{s}}\right)
\end{aligned}
$$

where, $\sigma, h_{s}$, and $w_{s}$ is the surface tension, the height of shallow channel, and the width of shallow channel, respectively. $\theta$ is the contact angle and the subscripts $T$, $B, L$, and $R$ indicate the top, bottom, left and right surface of the shallow channel, respectively. $\beta$ is the expansion angle in the width direction. In these equations, the solution may move forward toward the deep channel-B when the capillary pressure at the neck, $\Delta P_{n}$, is positive, and stop at the neck when $\Delta P_{n}$ is negative. In this paper, $\beta$ of $90^{\circ}$ and the value of the surface tension with $0.025 \mathrm{~N} / \mathrm{m}$ was used for $70 \%$ ethanol [28]. In addition, the contact angles were measured from the PDMS substrate (for $\theta_{T}$, $\theta_{L}$, and $\theta_{R}, \sim 60^{\circ}$ ) and glass substrate (for $\theta_{B}, \sim 45^{\circ}$ ). As a result, the capillary stop pressure at the neck is induced and the solution could not move forward toward the cell chamber (deep channel). After the solution stop at the neck, the evaporation of the solvent happened through the cell chamber. Then the convective transport of microspheres was caused from the source channel toward the neck to compensate of the solvent loss by evaporation. This influx of the microspheres then promotes the growth of the ordered lattice (FCC structure) from neck to the source channel in unidirectional. When the growth of microspheres assembly reached the interface between the shallow channel and the source channel, the residual solution in source channel was gently removed by withdrawing. Finally, self-assembled microspheres were dried out in room temperature for 1 day. The micro-interstices formed in these closed-packed microspheres of homogeneous sizes, which consist of equivalent micropores ( $15 \%$ of the sphere size) [29], serve as the diffusion channels.

\section{Preparation of bacteria cells}

Engineered attenuated $S$. typhimurium defective in guanosine 5'-diphosphate-3'-diphosphate (ppGpp) synthesis ( $\Delta$ ppGpp strain) used to express the bacterial luciferase gene lux for generating imaging signals was used in a chemotaxis experiment $[14,30]$. Cells were cultured overnight in $5 \mathrm{~mL}$ of Luria-Bertani (LB) medium (Fisher, Pittsburgh, PA, USA) supplemented with $50 \mu \mathrm{g} / \mathrm{mL}$ ampicillin and kanamycin at $37{ }^{\circ} \mathrm{C}$ in an incubator with shaking at $200 \mathrm{rpm}$. A $1 \%$ culture of the bacterial solution in LB medium containing ampicillin and kanamycin was prepared. Then, cells were incubated in a shaking incubator $\left(37^{\circ} \mathrm{C}, 200 \mathrm{rpm}\right)$ for $3-4 \mathrm{~h}$ until the $600 \mathrm{~nm}$ optical density $\left(\mathrm{OD}_{600}\right)$ of the cell culture reached 1.0. Finally, the cells were centrifuged at $3000 \mathrm{rpm}$ at room temperature and resuspended in M9 medium (minimal salt, BD, NJ,
USA.) containing the $10^{-3} \mathrm{M}$ of glucose. $\mathrm{M} 9$ medium is used for making minimal media so that it can provide the basic ionic buffering for the cells, and also provide an environment with comfortable osmotic properties. Therefore, bacteria can be grown until they are cultured in LB medium and they can maintain their population in M9 medium. From this, we can suppress an error which resulted from the increase of bacterial populations during reacting with amino acids. Before cells were loaded, the cell chamber was coated for $2 \mathrm{~h}$ with Pluronic surfactant (F-127, 1 \%, Sigma-Aldrich, St. Louis, MO, USA) to minimize any nonspecific binding between the cells and the glass surface and subsequently rinsed with M9 medium. Finally, the prepared cell suspension was loaded into the cell chamber.

\section{Experimental setup and data analysis}

FITC fluorescence dye diluted in M9 medium was used to characterize the proposed microfluidic device. For the amino acids, $\alpha$-methyl-DL-aspartic acid and L-arginine were purchased from Sigma-Aldrich, USA, and L-seine and L-alanine were purchased from Daejung Chemicals \& Metals, Korea. All amino acids were diluted in M9 medium before using as sources for chemoattractant. The fluorescence intensities could be quantitatively assessed from the captured images using ImagePro Plus (MediaCybernetics, Bethesda, MD, USA) software. A precise microsyringe pump (NE-1000, New Era Pump System, USA) was employed to control the flow rate in the source/sink channel through the microtubes. The cells behavior was monitored using an inverted microscope (IX7, Olympus Co., Tokyo, Japan) and images were captured using a CCD camera (CoolSNAP, Photometrices, Tucson, AZ, USA) installed in the microscope. To quantify the cell count, the same method was used as our previously published paper [14]. Briefly, same amounts of drops containing GFP-expressing S. typhimurium with different normalized concentrations were loaded into the open-cylinder type reservoir and the numbers of cells were calibrated by analyzing the fluorescent intensity. Finally, the fluorescent intensities at three different areas in the cell chamber were measured and then converted into the number of cells. For all statistical tests, analysis was performed using SigmaPlot software, and a $p$ value of $<0.05$ was considered significant. All data is presented as the mean \pm the standard error of the mean (SEM).

\section{Results and discussions}

The picture of the fabricated PDMS microfluidic channels with microchannel networks membrane (MCNM) and an enlarged microscopic image around the center chamber are shown in Fig. 2d. The source channels and the cell chamber are isolated by the MCNM. In order to 


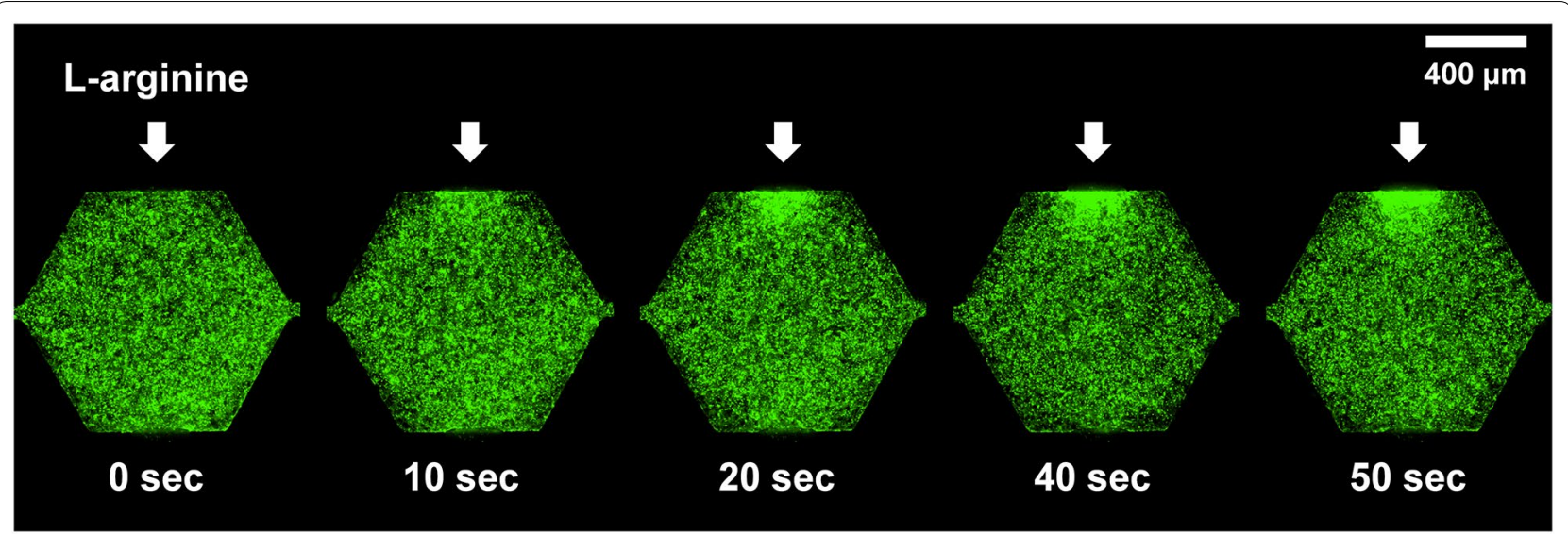

Fig. 3 Time sequence images for response of GFP-tagged S. typhimurium toward L-arginine. Bacterial cells show the positive response to the L-arginine with the concentration of $250 \mathrm{mM}$

characterize the device, the diffusivity of MCNM was tested using fluorescence dye (FITC). First, the base solution (M9 medium) was filled into the whole device. The fluorescence dye was then introduced into the three source channel $\left(90^{\circ}, 210^{\circ}\right.$, and $\left.330^{\circ}\right)$. Subsequently, the flow rate of $4.0 \mu \mathrm{L} / \mathrm{min}$ was controlled by withdrawing the solution to maintain the concentration. Finally, the stable concentration of FITC was established across the cell chamber in the three different directions because there was no net flow in the cell chamber but there was the diffusion of fluorescence dyes through the MCNM. Figure 2e shows the fluorescence images at the steadystate and Fig. $2 \mathrm{f}$ shows one of representative plots of the normalized fluorescence intensity profiles across the cell chamber as a function of time. The steady-state gradients were established within $1 \mathrm{~min}$ and were maintained for several minutes. In this paper, the proposed device was suitable for the chemotactic study for bacterial cells because $S$. typhimurium showed the chemotactic response toward the amino acids within $80 \mathrm{~s}$.

To demonstrate the capability of chemotaxis study using the proposed device, the behavior of S. typhimurium toward the single amino acid was observed. The $\mathrm{L}$-arginine was injected into the source channel at $90^{\circ}$ and M9 medium was introduce at the others and the flow was then controlled by withdrawing the solution to maintain the solution concentration in source/sink channels. Finally, bacterial cells were loaded into the cell chamber and images were then acquired for $60 \mathrm{~s}$. As a result, $S$. typhimurium showed the positive response to the $\mathrm{L}$-arginine in the presence of the concentration of $250 \mathrm{mM}$ (Fig. 3).

In order to verify a chemotactic preference of S. typhimurium when exposed the multiple cancer secreting amino acids, the reference values of amino acid concentration in serum from breast cancer patients and healthy donors were investigated [13]. Among these amino acids, the aspartate, the serine, and the alanine were chosen, which have lowest values of the threshold concentration (concentration of attractant that induces an accumulation of bacteria in the capillary significantly greater than that obtained absence of attractant) as previous studies showed [31]. Table 1 shows the reference values of threshold concentration of amino acid [31] and secreted concentration from health donors and breast cancer patients [13].

As shown in Fig. 4a, serine $(1.60 \mathrm{mM})$, aspartate $(0.17 \mathrm{mM})$, and alanine $(6.42 \mathrm{mM})$ diluted in $\mathrm{M} 9$ medium were introduced into the each source channel at $90^{\circ}, 210^{\circ}$, and $330^{\circ}$, respectively. The concentrations of amino acids were determined by reference values of the breast cancer patients shown in Table $1.50 \mathrm{~s}$ after loading the S. typhimurium into the cell chamber, bacterial

Table 1 Threshold concentration of amino acid and secreted concentration from health donors and breast cancer patients

\begin{tabular}{llll}
\hline $\begin{array}{l}\text { Amino } \\
\text { acid }\end{array}$ & $\begin{array}{l}\text { Threshold }^{\mathbf{a}} \\
(\mathbf{m M})\end{array}$ & $\begin{array}{l}\text { Health donors } \\
\mathbf{( \mathbf { m M } )}\end{array}$ & $\begin{array}{l}\text { Breast cancer }^{\mathbf{m}} \\
\text { patients }^{\mathbf{b}} \mathbf{( m \mathbf { M } )}\end{array}$ \\
\hline Aspartate & $\sim 0.002$ & $\sim 0.11$ & $\sim 0.17$ \\
Serine & $\sim 0.002$ & $\sim 1.32$ & $\sim 1.60$ \\
Alanine & $\sim 0.002$ & $\sim 3.92$ & $\sim 6.42$ \\
Glutamine & $\sim 0.1$ & $\sim 2.69$ & $\sim 3.91$ \\
Glutamate & $\sim 0.004$ & $\sim 0.59$ & $\sim 1.08$ \\
Aspargine & $\sim 0.01$ & $\sim 0.36$ & $\sim 0.41$ \\
Arginine & $\sim 1$ & $\sim 0.71$ & $\sim 0.93$
\end{tabular}

a Reference values from the Adler capillary assay [31]

b Reference values from high performance liquid chromatography and fluorescence detection [13] 


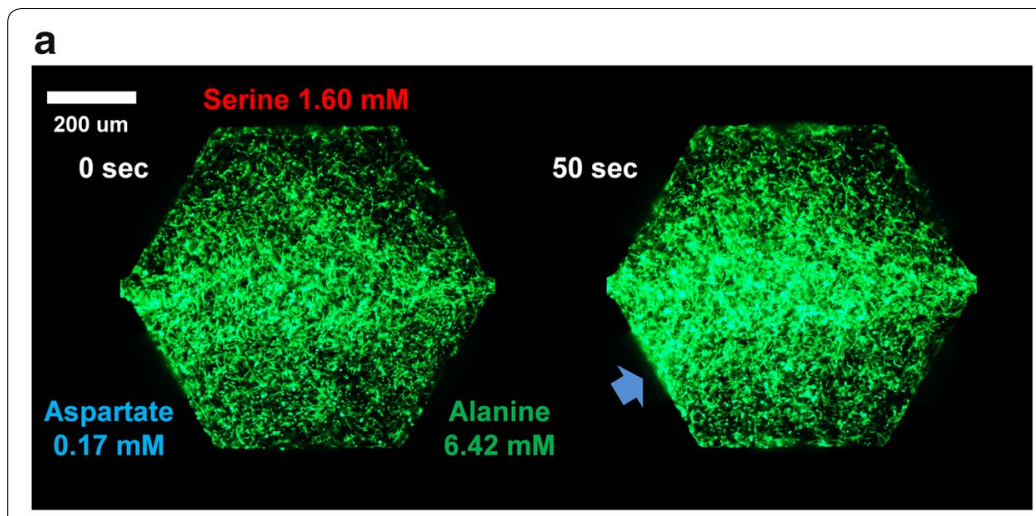

b

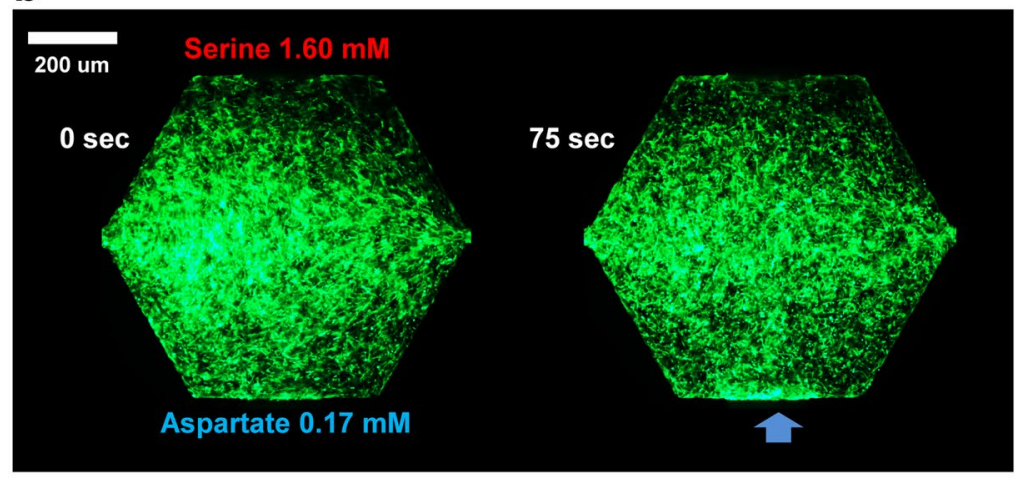

c

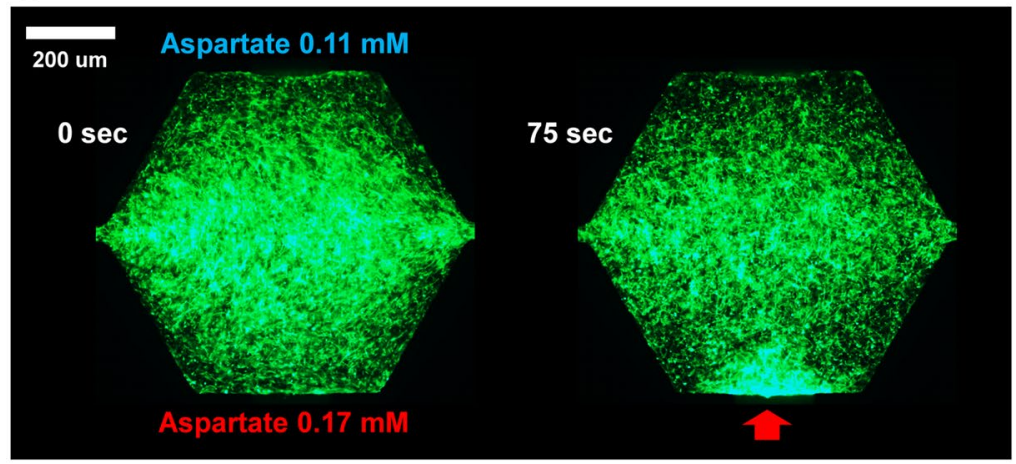

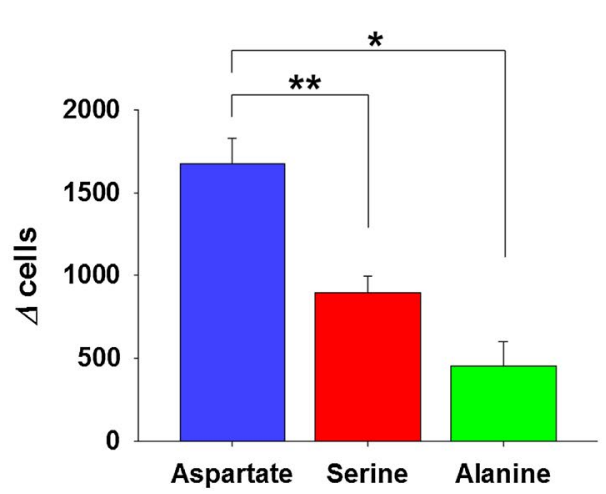
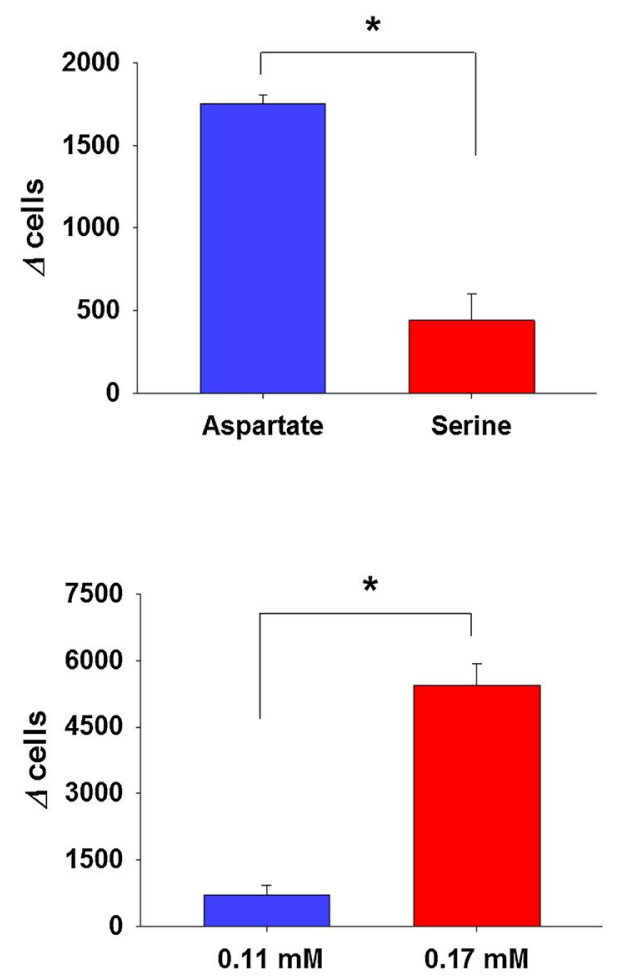

Fig. 4 Time sequence images for response of S. typhimurium toward representative cancer secreting amino acids and its corresponding bar plots for the changing of the number of cells. a Chemotactic response towards aspartate, serine and alanine with concentration values from breast cancer patients. b Chemotactic response towards aspartate and serine with concentration values from breast cancer patients. c Chemotactic response towards aspartate with concentration value from normal human versus breast cancer patients. Mean $\pm \mathrm{SEM}, *: 00.001,{ }^{* *}:=0.007$

cells showed the strongest positive chemotactic response toward the aspartate despite having a lowest concentration. Furthermore, by quantifying the changing the number of cells $(\Delta$ cells $), S$. typhimurium seems sensitive to the aspartate, serine and alanine, in this manner. Here, three amino acids were compared using one-way analysis of variance (ANOVA), with Tukey's post hoc tests for multiple comparisons $(\mathrm{n}=6$, mean \pm SEM, " : $<0.001$, $* *:=0.007)$.
To confirm this preference, the experiment for the chemotactic response toward the aspartate versus the serine was performed as shown in Fig. 4b. The serine $(1.60 \mathrm{mM})$ and the aspartate $(0.17 \mathrm{mM})$ diluted in $\mathrm{M} 9$ medium were injected into the source channel at $90^{\circ}$ and $270^{\circ}$, respectively, and the bacterial cells were then loaded into the center chamber. Each concentration of amino acid was the same as breast cancer patients shown in Table 1. Consequently, the quantitatively counted 
cells data reveals that the aspartate is most sensitive chemoattractant for the S. typhimurium ( $t$ tests, $\mathrm{n}=6$, mean \pm SEM, ${ }^{*}:<0.001$ ).

Finally, the bacterial preferential behavior against the released aspartate concentration from breast cancer patients and healthy donors were investigated. The aspartate concentrations of 0.11 and $0.17 \mathrm{mM}$ were chosen for health donors and cancer cell patients, respectively [13]. As shown in Fig. 4c, S. typhimurium showed strong positive chemotactic response toward the concentration gradient of aspartate at the cancer patient level ( $t$ tests, $\mathrm{n}=6$, mean \pm SEM, $\left.{ }^{*}:<0.001\right)$. This result shows the possibility that the concentration gradients of released aspartate from tumor can be crucial for targeting the tumor by S. typhimurium. Moreover, these results are reasonable as comparing with in vitro experiment by using tumor cylindroids model and S. typhimurium which individual chemoreceptors were knockout [1]. The results showed that the aspartate receptor initiated chemotaxis toward tumor cylindroids, the serine receptor initiated penetration, and the ribose/galactose receptor directed S. typhimurium toward necrosis. Previously, we demonstrated that the S. typhimurium showed more strong response toward the aspartate than to the ribose/galactose [2], the results altogether, therefore, the aspartate could be the one of the essential role for targeting S. typhimurium to the specific tumors.

\section{Conclusions}

The chemotactic preference of S. typhimurium for the tumor secreting amino acids, especially for the breast cancer was investigated. The candidate amino acids with the specific concentration values from breast cancer patients were introduced simultaneously into the multiple chemicals gradients generator which was constructed by spatially controlled self-assembly of particles in microchannels. After quantitative analyzing the chemotactic motion of S. typhimurium, we could conclude that $S$. typhimurium has strongest responsive toward the aspartic acid. This understanding chemotactic response to the cancer secreting amino acids will allow the development of bacterial therapies by utilizing the drug producible engineered bacteria or the bacteria-based micro-robot (bacteriobot) $[3,4,32,33]$ as enhancing the speed and precisely controlling the direction of bacteria.

\section{Authors' contributions}

EC designed and fabricated the microfluidic device and carried out experiments as a main author. BM, JL, HC supported fabrication, experiments and analysis the data. JP is a principle investigator in this research. All authors read and approved the final manuscript.

\section{Acknowledgements}

We wish to thank Dr. Seok-Ho Park and Dr. Jung-Joon Min in Chonnam National University for providing bacterial cells and Dr. Jinwon Lee in Sogang
University for helping with culturing the bacteria. Also thanks to Cong Wang in Sogang University for preparing the devices. This work was supported by Pioneer Research Center Program (2012-0001032) and a National Research Foundation of Korea (NRF) grant funded by the Korean government (MSIP) (NRF-2013R1A1A2073271, NRF-2015R1A2A2A04006181).

\section{Competing interests}

The authors declare that they have no competing interests.

Received: 1 August 2016 Accepted: 6 October 2016

Published online: 15 October 2016

\section{References}

1. Kasinskas RW, Forbes NS (2007) Salmonella typhimurium lacking ribose chemoreceptors localize in tumor quiescence and induce apoptosis. Cancer Res 67:3201-3209

2. Kasinskas RW, Forbes NS (2006) Salmonella typhimurium specifically chemotax and proliferate in heterogeneous tumor tissue in vitro. Biotechnol Bioeng 94:710-721

3. Huh K, Oh D, Son SY, Yoo HJ, Song B, Cho, D.-i.D., Seo, J.-M. \& Kim, S.J. (2016) Laminar flow assisted anisotropic bacteria absorption for chemotaxis delivery of bacteria-attached microparticle. Micro Nano Syst Lett 4:1-9

4. Park SJ, Park SH, Cho S, Kim DM, Lee Y, Ko SY, Hong Y, Choy HE, Min JJ, Park JO, Park S (2013) New paradigm for tumor theranostic methodology using bacteria-based microrobot. Sci Rep 3:3394

5. Giaccia AJ (1996) Hypoxic stress proteins: survival of the fittest. Semin Rad Oncol 6:46-58

6. Kim JJ, Tannock IF (2005) Repopulation of cancer cells during therapy: an important cause of treatment failure. Nat Rev Cancer 5:516-525

7. Lefevre CT, Bernadac A, Yu-Zhang K, Pradel N, Wu LF (2009) Isolation and characterization of a magnetotactic bacterial culture from the Mediterranean Sea. Environ Microbiol 11:1646-1657

8. Forbes NS, Munn LL, Fukumura D, Jain RK (2003) Sparse initial entrapment of systemically injected Salmonella typhimurium leads to heterogeneous accumulation within tumors. Cancer Res 63:5188-5193

9. Mei S, Theys J, Landuyt W, Anne J, Lambin P (2002) Optimization of tumor-targeted gene delivery by engineered attenuated Salmonella typhimurium. Anticancer Res 22:3261-3266

10. Min JJ, Nguyen VH, Kim HJ, Hong YJ, Choy HE (2008) Quantitative bioluminescence imaging of tumor-targeting bacteria in living animals. Nat Protoc 3:629-636

11. Yoo JW, Irvine DJ, Discher DE, Mitragotri S (2011) Bio-inspired, bioengineered and biomimetic drug delivery carriers. Nat Rev Drug Discov 10:521-535

12. Le UN, Kim HS, Kwon JS, Kim MY, Nguyen VH, Jiang SN, Lee BI, Hong Y, Shin MG, Rhee JH, Bom HS, Ahn Y, Gambhir SS, Choy HE, Min JJ (2011) Engineering and visualization of bacteria for targeting infarcted myocardium. Mol Ther 19:951-959

13. Poschke I, Mao Y, Kiessling R, de Boniface J (2013) Tumor-dependent increase of serum amino acid levels in breast cancer patients has diagnostic potential and correlates with molecular tumor subtypes. J Transl Med 11:290

14. Choi E, Chang HK, Lim CY, Kim T, Park J (2012) Concentration gradient generation of multiple chemicals using spatially controlled self-assembly of particles in microchannels. Lab Chip 12:3968-3975

15. Ling Y, Rubin J, Deng Y, Huang C, Demirci U, Karp JM, Khademhosseini A (2007) A cell-laden microfluidic hydrogel. Lab Chip 7:756-762

16. Hong JW, Song S, Shin JH (2013) A novel microfluidic co-culture system for investigation of bacterial cancer targeting. Lab Chip 13:3033-3040

17. Choi E, Jun I, Chang HK, Park KM, Shin H, Park KD, Park J (2012) Quantitatively controlled in situ formation of hydrogel membranes in microchannels for generation of stable chemical gradients. Lab Chip 12:302-308

18. Atencia J, Morrow J, Locascio LE (2009) The microfluidic palette: a diffusive gradient generator with spatio-temporal control. Lab Chip 9:2707-2714

19. Morel M, Galas JC, Dahan M, Studer V (2012) Concentration landscape generators for shear free dynamic chemical stimulation. Lab Chip 12:1340-1346 
20. Mosadegh B, Agarwal M, Tavana H, Bersano-Begey T, Torisawa Y, Morell M, Wyatt MJ, O'Shea KS, Barald KF, Takayama S (2010) Uniform cell seeding and generation of overlapping gradient profiles in a multiplexed microchamber device with normally-closed valves. Lab Chip 10:2959-2964

21. Yang CG, Wu YF, Xu ZR, Wang JH (2011) A radial microfluidic concentration gradient generator with high-density channels for cell apoptosis assay. Lab Chip 11:3305-3312

22. Choi E, Kwon K, Kim D, Park J (2015) Tunable reverse electrodialysis microplatform with geometrically controlled self-assembled nanoparticle network. Lab Chip 15:168-178

23. Choi E, Kwon K, Kim D, Park J (2015) An electrokinetic study on tunable 3D nanochannel networks constructed by spatially controlled nanoparticle assembly. Lab Chip 15:512-523

24. Choi E, Kwon K, Lee SJ, Kim D, Park J (2015) Non-equilibrium electrokinetic micromixer with 3D nanochannel networks. Lab Chip 15:1794-1798

25. Choi E, Wang C, Chang GT, Park J (2016) High current ionic diode using homogeneously charged asymmetric nanochannel network membrane. Nano Lett 16:2189-2197

26. Chung S, Yun H, Kamm RD (2009) Nanointerstice-driven microflow. Small 5:609-613
27. Cho H, Kim H-Y, Kang JY, Kim TS (2007) How the capillary burst microvalve works. J Colloid Interface Sci 306:379-385

28. Vazquez G, Alvarez E, Navaza JM (1995) Surface tension of alcohol water+water from 20 to $50{ }^{\circ} \mathrm{C}$. J Chem Eng Data 40:611-614

29. Zeng Y, Harrison DJ (2007) Self-assembled colloidal arrays as threedimensional nanofluidic sieves for separation of biomolecules on microchips. Anal Chem 79:2289-2295

30. Nguyen VH, Kim HS, Ha JM, Hong YJ, Choy HE, Min JJ (2010) Genetically engineered Salmonella typhimurium as an imageable therapeutic probe for cancer. Cancer Res 70:18-23

31. Melton T, Hartman PE, Stratis JP, Lee TL, Davis AT (1978) Chemotaxis of Salmonella typhimurium to amino acids and some sugars. J Bacteriol 133:708-716

32. Yoo H, Lee S, Cho D-I (2014) Motility control of bacteria-actuated biodegradable polymeric microstructures by selective adhesion methods. Micromachines 5:1287

33. Park SJ, Bae H, Ko SY, Min J-J, Park J-O, Park S (2013) Selective bacterial patterning using the submerged properties of microbeads on agarose gel. Biomed Microdevices 15:793-799

\section{Submit your manuscript to a SpringerOpen ${ }^{\odot}$ journal and benefit from:}

- Convenient online submission

- Rigorous peer review

- Immediate publication on acceptance

- Open access: articles freely available online

- High visibility within the field

- Retaining the copyright to your article 